\title{
Face masks release water vapour but where does it go? An early observational study
}

Stubington T.J. ${ }^{1}$, Sahota R.S. ${ }^{2}$, Mottacki N. ${ }^{3}$, Johnston M.N. ${ }^{4}$, Judd $O^{5}$.

1. MBBS, BMedSci, MRCS(ENT), PGCert (MedEd), Department of Otorhinolaryngology - Head and Neck Surgery, Royal Derby Hospital, Uttoxeter Road, Derby, DE22 3NE, United Kingdom

2. MD, FRCS (ORL-HNS) Department of Otorhinolaryngology - Head and Neck Surgery, Royal Derby Hospital, Uttoxeter Road, Derby, DE22 3NE, United Kingdom

3. MBChB, Sahlgrenska Academy, University of Gothenburg, Institute of Medicine, Department of Internal Medicine and Clinical Nutrition, Gothenburg, Sweden

4. MBChB, BSC (Hons), FRCS (ORL-HNS), Department of Otorhinolaryngology - Head and Neck Surgery, Royal Derby Hospital, Uttoxeter Road, Derby, DE22 3NE, United Kingdom

5. FRCP, FRCS, FRCS (ORL-HNS), FRSA, Department of Otorhinolaryngology - Head and Neck Surgery, Royal Derby Hospital, Uttoxeter Road, Derby, DE22 3NE, United Kingdom 


\begin{abstract}
Objectives:

The aim of this observational study was to demonstrate the behaviour and trajectory of exhaled material from an individual wearing an FFP3 mask. Valves allow material release, but we theorised that valve design may direct material downwards towards patient and surrounding environment.

Limiting transmission of diseases with aerosolised spread is a current and serious concern within healthcare worldwide. Filtering face piece masks (FFP) are an essential piece of protective equipment when treating patients with ongoing infection. However, valved masks in other settings such as elective theatre and by the general public may have unforeseen negative effects.
\end{abstract}

Design:

A heating coil-based vaporiser was used to produce visible water vapour. A healthy test subject was filmed wearing a variety of different masks and exhaling the water vapour.

Results:

Flexible pleated and solid-shell FFP masks direct exhaled material downwards in plumes exceeding $25 \mathrm{~cm}$. Duckbill-shaped masks appear to direct exhaled vapour laterally, with a smaller plume. The effect is influenced by mask design and type of valve. Fluid repellent surgical masks reduce material directed downwards, and when used in conjunction with an FFP3 mask, appear to reduce the size and density of the exhaled vapour plume. The use of a visor was ineffective in reducing plume expulsion.

Interpretation:

A properly fit-tested FFP3-rated protective mask may only moderately limit expulsion of aerosolised particles from asymptomatic healthcare workers to patients, particularly in cases where procedures are being performed in close proximity to patients or in cases where mucosal surfaces are exposed. Further research in this area is needed.

\title{
Keywords
}

COVID-19, Filtering Face Piece mask, Infection control, Aerosol, Droplet

\section{Acknowledgements}

All of the credited authors are members of D.R.A.G.O.N the Derbyshire Rapid Aerosol Generating Observational Network. A research group set up by clinicians and researchers to explore aerosolisation using high speed video photography. This organisation is voluntary and no authors received any financial incentive to be a member nor has the D.R.A.G.O.N Organisation received any funding to date. 


\section{Introduction}

Limiting transmission of diseases with aerosolised spread is a current and serious concern within healthcare worldwide. Recent developments - foremost among which is the emergence of the novel coronavirus SARS-CoV-2 - have led to the adoption of multiple strategies to limit the spread of infection in healthcare environments. These concerns, however, have been primarily focused on limiting transmission from patients to healthcare professionals. Three transmission routes of respiratory pathogens are described in the literature; (1) contact transmission (transmission through direct contact with a positive case or indirect contact via an object or surface), (2) droplet transmission (respiratory droplets from a positive case making contact with a mucosal surface), and (3) aerosol transmission (inhalation of small droplets that are suspended in the air as an aerosol) ${ }^{3}$. MERS, SARS, influenza viruses and a number of other organisms have been studied but there remains a dearth of high-quality evidence to clearly demonstrate the relative significance of each method of transmission ${ }^{3,4}$.

It has proven difficult to accurately quantify the infection vectors of virulent respiratory pathogens. Most responses to SARS-CoV-2 have included social restrictions intended to combat all 3 potential methods of transmission ${ }^{5,6}$. Self-isolation of vulnerable individuals, reductions in movements outside the home and a policy of maintaining distance between individuals reduces the opportunities for direct spread by touch. Rigorous cleaning of surfaces and hand washing reduces indirect spread. The wearing of water-resistant face masks limits the expulsion of respiratory droplets and hence droplet spread. Filtering face piece masks limit spread by inhalation by protecting those in direct contact with infected patients from aerosolised material which may contain the virus.

Previous pandemics such as SARS (caused by the coronavirus SARS-CoV-1) have demonstrated significant healthcare worker infection rates as a result of aerosol-generating procedures (AGPS) ${ }^{7}$. This trend is mirrored by COVID19 (caused by SARS-CoV-2), with rising numbers of healthcare worker deaths worldwide ${ }^{8,9}$. The National Health Service in the UK has taken extensive measures to prevent healthcare workers from contracting SARS-CoV-2 in the work setting. ${ }^{8}$ A key component of these measures is the provision of FFP masks. These protect the wearer from the external environment but particularly in the case of valved masks they do not protect the environment from the user's exhaled material ${ }^{10}$. We present the results of an observational study which provides a visual representation of the material ejected from a user wearing a variety of masks, as well as the effect of valves in redirecting this material. We also provide a number of possible interventions to limit the negative impact of valved masks for those individuals unable to wear an alternative unvalved FFP3 mask. 
medRxiv preprint doi: https://doi.org/10.1101/2020.08.09.20154435; this version posted August 13, 2020. The copyright holder for this preprint (which was not certified by peer review) is the author/funder, who has granted medRxiv a license to display the preprint in perpetuity.

\author{
It is made available under a CC-BY-NC-ND 4.0 International license .
}

\title{
Methods
}

Four different FFP3 masks and a standard fluid-resistant surgical mask were tested. Each mask was produced by a different manufacturer. In the study they are described by a unique identifying letter for the duration of the paper. Table 1 shows the characteristics of each mask.

A healthy clean-shaven male test subject in his 20 s (non-smoker, no known respiratory illnesses, no current medications, average peak expiratory flow of $720 \mathrm{l} / \mathrm{min}$ ) was used to demonstrate the effects of each mask. The test subject had been appropriately fit tested to all of the masks. Fit testing was previously performed and complied with local hospital procedure. Prior to testing each of the masks were applied to the test subject's face, adjusted and the fit was confirmed by sharp exhalation through the nose observing for misting of eyewear. A heating coil-based handheld vaporiser (Smok ${ }^{\circledR}$ RPM 40 , battery capacity $1500 \mathrm{mAh}$, power set to 40 watts) was used to produce visible water vapour during exhalation. The test subject then fitted each mask in turn, lifted the base to introduce the vaporiser, held their breath while the mask fit was readjusted and then exhaled gently and passively over approximately 5 seconds. Following initial testing of each mask potential additional measures to mitigate valve output were also performed using the same test procedure (table 2). Video recordings were taken using an iPhone 11 Pro using the on-board 12-megapixel camera system (Apple Inc., California) against a plain blue background in a sheltered outdoor space with no exposure to wind. All recordings were taken on the same day in the same location, during sunshine and with no clouds overhead, to ensure consistent lighting during testing. 


\section{Results (Table 3)}

\section{No mask (Table 3 row 0 )}

The image and video recording clearly demonstrate vapour flowing in an antero-inferior trajectory. The vapour travels in excess of $60 \mathrm{~cm}$ from the mouth of the subject (Table 3 Row 0 ).

\section{Mask A (Table $3 \operatorname{row} A)$}

The fluid resistant surgical mask was effective at directing exhaled vapour upwards and laterally while appearing to minimise inferior escape. There was no spread beyond $10 \mathrm{~cm}$ from the subject which could be visualised as aerosol vapour (Table 3 Row A, A1).

\section{Mask $B$ (Table 3 row $B$ )}

The valve in mask $B$ allows exhaled vapour straight through the flapped valve system (B1). It directs the vapour downwards; maximum distance was measured at $25 \mathrm{~cm}$ from the valve outlet. Applying a fluid resistant surgical mask was effective in diminishing output (B2). The plume of vapour was reduced to only a few centimetres and redirected upwards. Applying a visor (B3) in conjunction with mask $B$ allowed the vapour to concentrate. The thicker vapour was redirected downwards.

\section{Mask C (Table 3 row C)}

The valve allows exhaled vapour through the flapped system, directing it downwards. The maximum spread of the plume was greater than $25 \mathrm{~cm}$ from the test subject. The addition of the fluid resistant surgical mask provides an effective additional barrier (C2), leading to minimal escape.

Mask D (Table 3 row D)

Mask $D$ directed the plume for aerosol forward and upwards with maximum extent of the visible plume around $12 \mathrm{~cm}$ from the valve. When coupled with a fluid resistant mask (D2) minimal vapour was directed downwards and made the plume negligible. The use of a visor did not reduce the size and extent of the plume, instead predominantly directing the vapour upwards (D3).

\section{Mask E (Table 3 row E)}

The valveless FFP3 mask limited the amount of vapour escaping (E1). A small amount escaped laterally, but was so insignificant as to make it difficult to quantify its size from the recordings. There was very little projected downwards. When a fluid resistant surgical mask was applied over mask $\mathrm{E}$ there was an additive effect with even less vapour ejecting and projecting downwards (E2). Since there appeared to be an insignificant plume, particularly upon adding a surgical mask, we did not proceed with testing the addition of a visor. 


\section{Discussion}

Our findings show that there is continued expulsion of aerosolised material despite the wearing of valved FFP3-rated masks. In the cases where our test subject wore flexible pleated or solid-shell masks, we observed the continued ejection of aerosol plumes downwards (figure 1). Applying a surgical mask on top of the FFP3 mask significantly reduces the size of the plume, and redirects it laterally in all cases (figure 2). The application of a visor appears to cause added deleterious effects to the direction and thickness of vapour. Though our data does not allow exact quantification of the expelled material, the vapour was projected downwards in excess of $25 \mathrm{~cm}$ from the valve in both cases. In the case of the solid-shell mask, there appears to be a greater amount of vapour being ejected; we hypothesise that this may be due to the rigid nature of the mask funnelling the exhalation. The addition of a visor had potentially negative effects causing increased downwards projection of the plume. We were curious if the application of tape on the exhaust of the solid-shell mask would impact the escape of vapour (figure 3). However, despite repeated attempts we found this was not an effective technique to seal the valve. There was significant variation between different tape applications, but none prevented vapour escape.

Exhalation through the duckbill mask seemed to produce the smallest plume of the valved masks comparatively. These findings are not conclusive, but we hypothesise that the duckbilled shape of the mask diffuses aerosolised vapours prior to ejection.

This initial observational study is intended to provide a visual representation of a potential area of concern. Having observed the expulsion of droplets when using the recommended FFP3 masks, we have attempted to produce results to quantify the possibility of respiratory ejecta from healthcare workers using the currently recommended safety equipment. Further, this is highly relevant in the ongoing COVID-19 pandemic, with disease spread through aerosols having been demonstrated previously in other viruses ${ }^{11-14}$ and as yet unknown in SARS COV2 ${ }^{16}$. Much of the response to the highly virulent SARS-CoV-2 virus has focused on limiting person to person spread $^{16}$, though we have found no studies in the literature that assess the continued potential for aerosolised spread of the disease from healthcare workers to patients despite the use of protective equipment.

Viable respiratory viruses have been detected in droplets as small as $0.3 \mu \mathrm{m}$ and the size of droplets containing viable viruses seems to vary depending on the individual virus ${ }^{4,11-14}$ The particles produced by the vaporiser are reported to be in the range of $10 \mathrm{~nm}$ to $5 \mu \mathrm{m}^{17,18}$. Based on this size range and previously published data on other respiratory viruses it seems reasonable to conclude that droplets containing viable SARS-CoV2 could be released from these flutter valves into the surrounding environment.

Many countries around the world have made the wearing of face coverings mandatory in certain public places and within hospitals ${ }^{19}$. This has led the World Health Organisation supporting the use of non-medical face coverings in certain public settings despite a relative paucity of high quality evidence $^{16}$. As urgent and elective activity is being reintroduced, most UK hospitals have strict protocols in place to protect patients and vulnerable healthcare workers $\mathrm{s}^{20-21}$. It has been reported that asymptomatic or pre-symptomatic individuals can test positive for the virus and there have been reports of potential asymptomatic transmission ${ }^{2,22-25}$ In hospitals these masks are only recommended during aerosol generating procedures ${ }^{16}$. There are circumstances in which these findings, in conjunction with our results could be significant, such as if an asymptomatically positive healthcare worker wearing a valved mask is working in close proximity to a patient ${ }^{22}$. Although this is 
likely an uncommon occurrence, it has potentially catastrophic consequences for vulnerable patients, particularly those who are immunocompromised. Consideration should be given to the fact that the wearing of valved FFP3 masks to protect healthcare workers who are in contact with patients whose SARS-CoV-2 status is uncertain, represents a potential for continued spread of infection in the absence of more comprehensive precautions.

We are aware of the limitations of these results due to the absence of precision measurements, singular tests without repetition and variability in tidal volumes and force of exhalation. To an extent, these will have been minimised by using the same test subject and through attempting to standardise the evaluation protocol. It is difficult to draw definitive conclusions beyond comparing the vapour plume between the tests. In doing so, the images starkly demonstrate that in normal conditions, even in the absence of forced exhalation, the flutter valve permits exhaled material to enter the surrounding environment. Previous studies have demonstrated that fluid-repellent surgical masks are effective at directing exhaled material laterally and away from the patient ${ }^{15,26}$. Based on our results some FFP3 masks may instead be redirecting the exhaled material towards the patient. This may represent an increased risk of infection in cases where mucosal surfaces are exposed, e.g. during surgery or intubation. Further studies are mandatory to confirm and expand on our findings.

\section{Conclusion}

Wearing FFP3-rated protective masks does not appear to eradicate the exhalation of aerosolised vapours. These findings may be relevant - in conjunction with modified protection procedures - to limit the expulsion of aerosolised particles from asymptomatic healthcare workers to patients, particularly in cases where procedures are being performed in close proximity to patients or in cases where mucosal surfaces are exposed. In our testing, duckbill-shaped masks appear to release the smallest amount of aerosolised particles; the addition of a surgical mask to the FFP3 masks appears to mitigate the amount of the plume, and also redirects it from the patient. The use of visors conveyed no such benefits. Our initial findings need to be corroborated by further research. 
medRxiv preprint doi: https://doi.org/10.1101/2020.08.09.20154435; this version posted August 13, 2020. The copyright holder for this preprint (which was not certified by peer review) is the author/funder, who has granted medRxiv a license to display the preprint in perpetuity.

It is made available under a CC-BY-NC-ND 4.0 International license.

\section{Legends}

Table 1: This table describes the type of mask and relevant specific features and associates each mask with a unique identifying letter.

Table 2: This table details the combinations of masks and additional measures tested and associates each combination with an alphanumerical combination. This alphanumerical code identifies the video recording of this test combination which is available in supplementary material.

Table 3: The stills taken from each experiment demonstrate the combinations of mask and additional measures and the effects that these combinations had on respiratory ejecta.

Figure 1: Valved mask with no additional measures in place (test C1)

Figure 2: Valved mask with fluid resistant surgical mask placed over the top (test C2)

Figure 3: Tape applied over the valve of a valved mask (test C4). This proved ineffective as a solution to prevent exhaled material escaping.

Supplementary video 1: Control, subject exhaling with no mask (test 0 as referenced in table 2)

Supplementary video 2: Water resistant surgical mask only (test A1 as referenced in table 2)

Supplementary video 3: Valved mask with no additional measures in place (test $\mathrm{C} 1$ as referenced in table 2)

Supplementary video 4: Valved mask with fluid resistant surgical mask over the top (test C2 as referenced in table 2 )

Supplementary video 5: Valved mask with Visor (test C3 as referenced in table 2) 
medRxiv preprint doi: https://doi.org/10.1101/2020.08.09.20154435; this version posted August 13, 2020. The copyright holder for this preprint (which was not certified by peer review) is the author/funder, who has granted medRxiv a license to display the preprint in perpetuity.

It is made available under a CC-BY-NC-ND 4.0 International license .

\section{Author Contributions}

All credited authors were involved in the recording and acquisition of images

T Stubington wrote the majority of the article formatted the text for submission and prepared the non-photographic graphics for the paper

R Sahota arranged testing equipment, conducted an initial literature review and provided stylistic and content advice

N Mottacki wrote part of manuscript, providing stylistic and content advice

$M$ Johnston sourced materials and constructed testing environment and provided review of manuscript for content and style

O Judd highlighted initial concerns, devised project, wrote initial introduction and reviewed manuscript for content and style as well as writing initial draft of conclusions.

\section{Funding}

This research received no specific grant from any funding agency in the public, commercial, or notfor-profit sectors. No support was sought or received from academic institutions/grants or commercial organisations.

\section{Conflicts of interest}

The Author(s) declare(s) that there is no conflict of interest. None of the credited authors have any financial interests in any of the companies manufacturing the products tested in this study. No member of the study team sits on an advisory group or is part of a governing body that influences policy relating to personal protective equipment.

\section{Role of Medical Writer}

No medical writer was used at any point in the preparation of this manuscript all text was written by members of the research team.

\section{Patient and Other consent}

No patients or patient information was involved in this study. The individual in the video footage and still images is the first author Mr T Stubington who has fully consented to the use of their image and the dissemination of recordings and images for all purposes related to the publication of this article. This study was approved by the local ethics committee at the Royal Derby Hospital.

\section{Supplementary information}

Supplementary information is available for this paper in an online format. This comprises of the video recordings referenced in the text which can be viewed online. 


\section{References}

1. World Health Organisation. Report of the WHO-China Joint Mission on Coronavirus Disease 2019 (COVID-19). (2020).

2. He, X. Lau,E. Wu,P et. al "Temporal dynamics in viral shedding and transmissibility of COVID19".Nature Medicine 2020; 26; 672-675

3. Shiu, E. Y. C., Leung, N. H. L. \& Cowling, B. J. "Controversy around airborne versus droplet transmission of respiratory viruses: implication for infection prevention". Current Opinion in infectious Diseases 2019; 32; 372-379

4. Kutter, J. S., Spronken, M. I., Fraaij, P. L., Fouchier, R. A. \& Herfst, S. "Transmission routes of respiratory viruses among humans". Current Opinion in Virology 2018; 28; 142-151.

5. Remuzzi, A. \& Remuzzi, G. "COVID-19 and Italy: what next?" The Lancet 2020; 395; 12251228.

6. United Kingdom Government."Coronavirus (COVID-19) action plan". Government policy 2020; available at: https://www.gov.uk/government/publications/coronavirus-action-plan

7. Wong, T. W. "An outbreak of SARS among healthcare workers". Occupational and Environmental Medicine 2003; 60; 528.

8. Center for Disease Control."Characteristics of Health Care Personnel with COVID-19 - United States, February 12-April 9, 2020". Morbidity Mortality Weekly Report 2020; 69; 477-481. Wu,Z.McGoogan,JM. "Characteristics and important lessons from the Coronavirus Disease 2019 (COVID-19) Outbreak in China: Summary of a report of 72314 Cases from the Chinese Center for Disease Control and Prevention". Journal of American Medical Association 2020;323;1239-42 transmission from potentially asymptomatic or pre-symptomatic people through the use of face masks. 2020 Sellers RF, Parker J. "Airborne excretion of foot-and-mouth disease virus". Journal of Hygeine (London) 1969;67;671-7.

12. Noti J, Lindsley W, Francoise. "Detection of Infectious Influenza Virus in Cough Aerosols Generated in a Simulated Patient Examination Room". Clinical Infectious Diseases 2012;54;1569-77

13. Lindsley WG, Noti JD, Blachere FM, Thewlis RE, Martin SB, Othumpangat S, et al. "Viable influenza a virus in airborne particles from human coughs". Journal of Occupational and Environmental Hygeine 2015;12;107-13. Liquid, Impactor Type, and Substrate on Size-Selective Sampling of MS2 and Adenovirus Aerosols". Aerosol Science and Technology 2012;46;249-57. Leung NHL, Chu DKW, Shiu EYC, Chan K-H, McDevitt JJ, Hau BJP, et al. "Respiratory virus shedding in exhaled breath and efficacy of face masks". Nature Medicine 2020;26;676-80. World Health Organisation. "Advice on the use of masks in the community, during home care and in healthcare settings in the context of the novel coronavirus (COVID-19) outbreak". Available from: https://www.who.int/publications-detail/advice-on-the-use-of-masks-in-thecommunity-during-home-care-and-in-healthcare-settings-in-the-context-of-the-novelcoronavirus-(2019-ncov)-outbreak

17. Sosnowski, T. R. \& Odziomek, M. "Particle size dynamics: Toward a better understanding of electronic cigarette aerosol interactions with the respiratory system". Frontiers in Physiology 2018;9;853 
medRxiv preprint doi: https://doi.org/10.1101/2020.08.09.20154435; this version posted August 13, 2020. The copyright holder for this preprint (which was not certified by peer review) is the author/funder, who has granted medRxiv a license to display the preprint in perpetuity.

It is made available under a CC-BY-NC-ND 4.0 International license.

Meng, Q. Son, Y.Kipen, H.Laskin,D.Schwander,S.Delnevo,C.. "Particles Released from Primary ECigarette Vaping: Particle Size Distribution and Particle Deposition in the Human Respiratory Tract". American journal of respiratory critical care medicine 2017.

What are the rules for wearing face masks in other countries? Available at: https://www.telegraph.co.uk/news/2020/06/15/rules-wearing-face-masks-countries/. (Accessed: 30th June 2020)

The Royal College of Surgeons of England. Updated Intercollegiate General Surgery Guidance on COVID-19 [Internet]. 2020 [cited 2020 Jun 30]. Available from: https://www.rcseng.ac.uk/coronavirus/joint-guidance-for-surgeons-v2/

21. ENT UK. Exiting the pandemic: guidance for resuming ENT services [Internet]. London; 2020 [cited 2020 May 14]. Available from: https://www.entuk.org/exiting-pandemic-guidanceresuming-ent-services

Rivett L, Sridhar S, Sparkes D, Routledge M, Jones NK, Forrest S, et al. "Screening of healthcare workers for SARS-CoV-2 highlights the role of asymptomatic carriage in COVID-19 transmission". Elife 2020;9;DOI 10.7554/eLife.58728

Tong, Z. D. et al. "Potential presymptomatic transmission of SARS-CoV-2, Zhejiang Province, China, 2020". Emerging Infectious Diseases 2020; 26; 1052-1054.

Bai, Yao,L. Wei,T. Tian,F. et al "Presumed Asymptomatic Carrier Transmission of COVID-19". Journal of the American Medical Association 2020; 323; 1406-1407.

Arons, M. M. et al. "Presymptomatic SARS-CoV-2 Infections and Transmission in a Skilled Nursing Facility". New England Journal of Medicine 2020. 382;2081-90

Tang, J. W., Liebner, T. J., Craven, B. A. \& Settles, G. S. "A schlieren optical study of the human cough with and without wearing masks for aerosol infection control". Journal of Royal Society of Publishing, Interface 2009;6; 727-35. 
(C I)

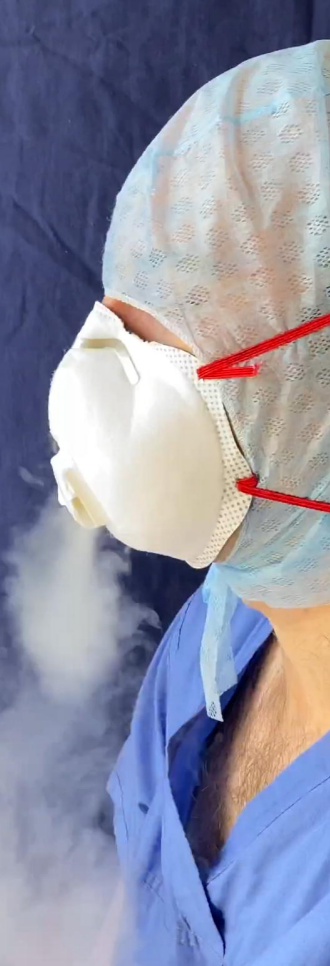


(C2) 
medRxiv preprint doi: hitps://doi.org/10.1101/2020.08.09.20154435; this version posted August 13,2020 . The copyright holder for this preprint
(which was not certified bv neer review) is the author/funder who has aranted medRxiv a license to disnlav the pronrint in nernetuity

(C4)

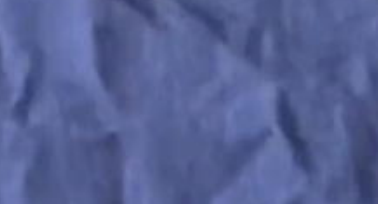


Figure 1: Features and Descriptions of Each of the Tested Masks

\begin{tabular}{|l|l|l|l|l|l|}
\hline Mask ID & $\begin{array}{l}\text { Protective } \\
\text { Level }\end{array}$ & Design & Valve? & Nose clip? & $\begin{array}{l}\text { Adjustable } \\
\text { straps? }\end{array}$ \\
\hline $\begin{array}{l}\text { No } \\
\text { mask }\end{array}$ & Nil & N/A & N/A & N/A & N/A \\
\hline A & $\begin{array}{l}\text { Surgical } \\
\text { mask }\end{array}$ & $\begin{array}{l}\text { Fluid resistant } \\
\text { surgical mask }\end{array}$ & No & No & No \\
\hline B & FFP3 & $\begin{array}{l}\text { Flexible } \\
\text { pleated } \\
\text { mask }\end{array}$ & Yes & Yes & No \\
\hline C & FFP3 & $\begin{array}{l}\text { Solid shell mask } \\
\text { Fes }\end{array}$ & Yes & Yes \\
\hline D & FFP3 & $\begin{array}{l}\text { Duck bill mask } \\
\text { pleated }\end{array}$ & Yes & Yes & No \\
\hline E & FFP3 & $\begin{array}{l}\text { Flexible } \\
\text { mask }\end{array}$ & Yes & No \\
\hline
\end{tabular}




\section{Table 2: Mask combinations tested}

\begin{tabular}{|l|l|l|}
\hline Video ID & Mask Description & Additional Measure \\
\hline 0 & No Mask (control) & Nil (control) \\
\hline A1 & Fluid resistant surgical mask & Nil \\
\hline B1 & Flexible pleated FFP3 with valve & Nil \\
\cline { 1 - 1 } B2 & & Fluid resistant mask \\
\cline { 1 - 1 } & & Visor \\
\hline B3 & \multirow{2}{*}{ Solid shell FFP3 valved mask } & Nil \\
\cline { 1 - 1 } C2 & & Fluid resistant mask \\
\cline { 1 - 1 } C3 & & Visor \\
\hline D1 & \multirow{2}{*}{ Duckbill FFP3 valved mask } & Nil \\
\cline { 1 - 1 } D2 & & Fluid resistant mask \\
\cline { 1 - 1 } & & Visor \\
\hline D3 & & Nil \\
\hline E1 & Flexible pleated FFP3 no valve & \\
\cline { 1 - 1 } & & Fluid resistant mask \\
\hline E2 & & \\
\hline
\end{tabular}


medRxiv preprint doi: https://doi.org/10.1101/2020.08.09.20154435; this version posted August 13, 2020. The copyright holder for this preprint (which was not certified by peer review) is the author/funder, who has granted medRxiv a license to display the preprint in perpetuity.

It is made available under a CC-BY-NC-ND 4.0 International license. 
Table 3: Pictoral representations of each experimental phase

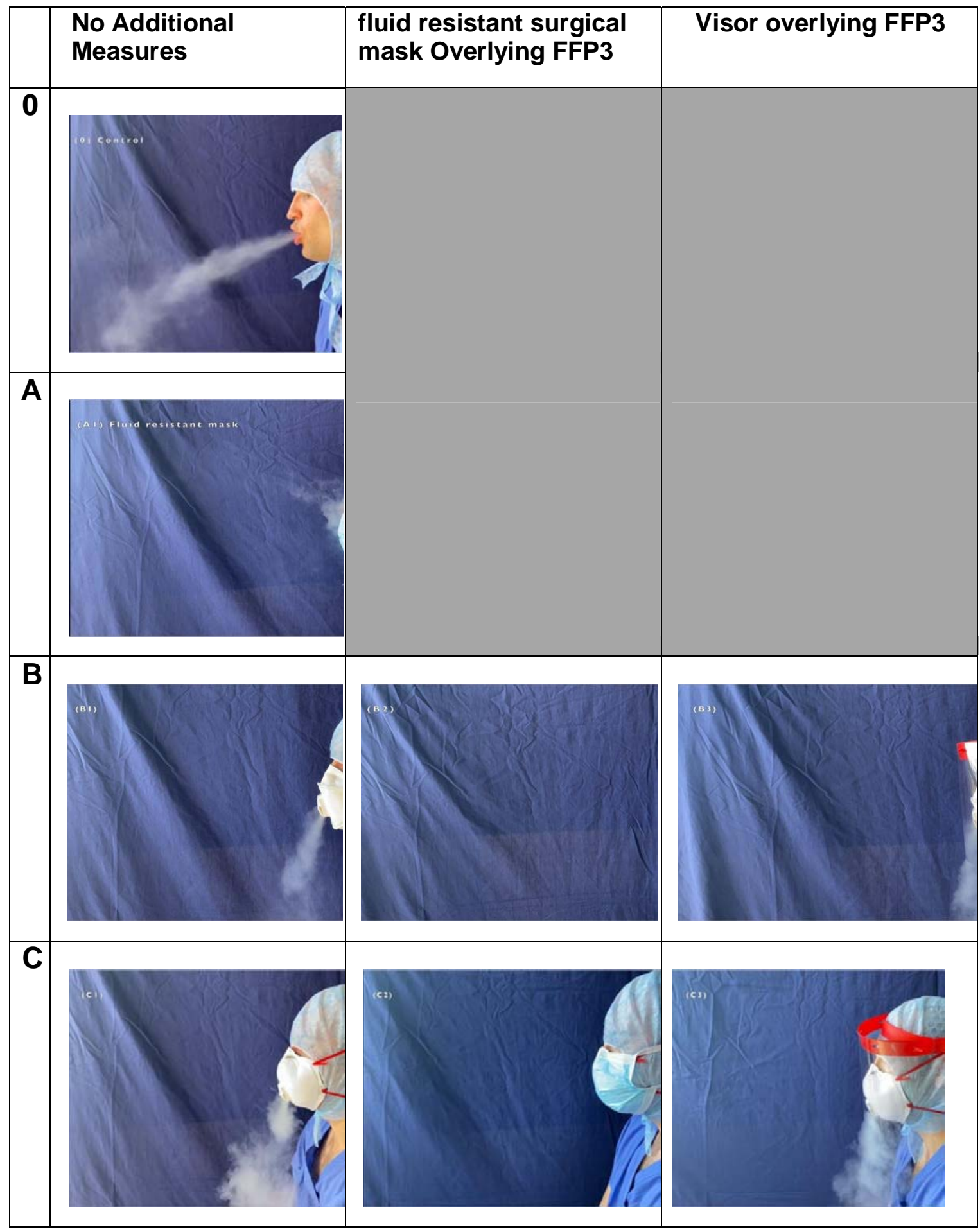


medRxiv preprint doi: https://doi.org/10.1101/2020.08.09.20154435; this version posted August 13, 2020. The copyright holder for this preprint (which was not certified by peer review) is the author/funder, who has granted medRxiv a license to display the preprint in perpetuity.

It is made available under a CC-BY-NC-ND 4.0 International license .

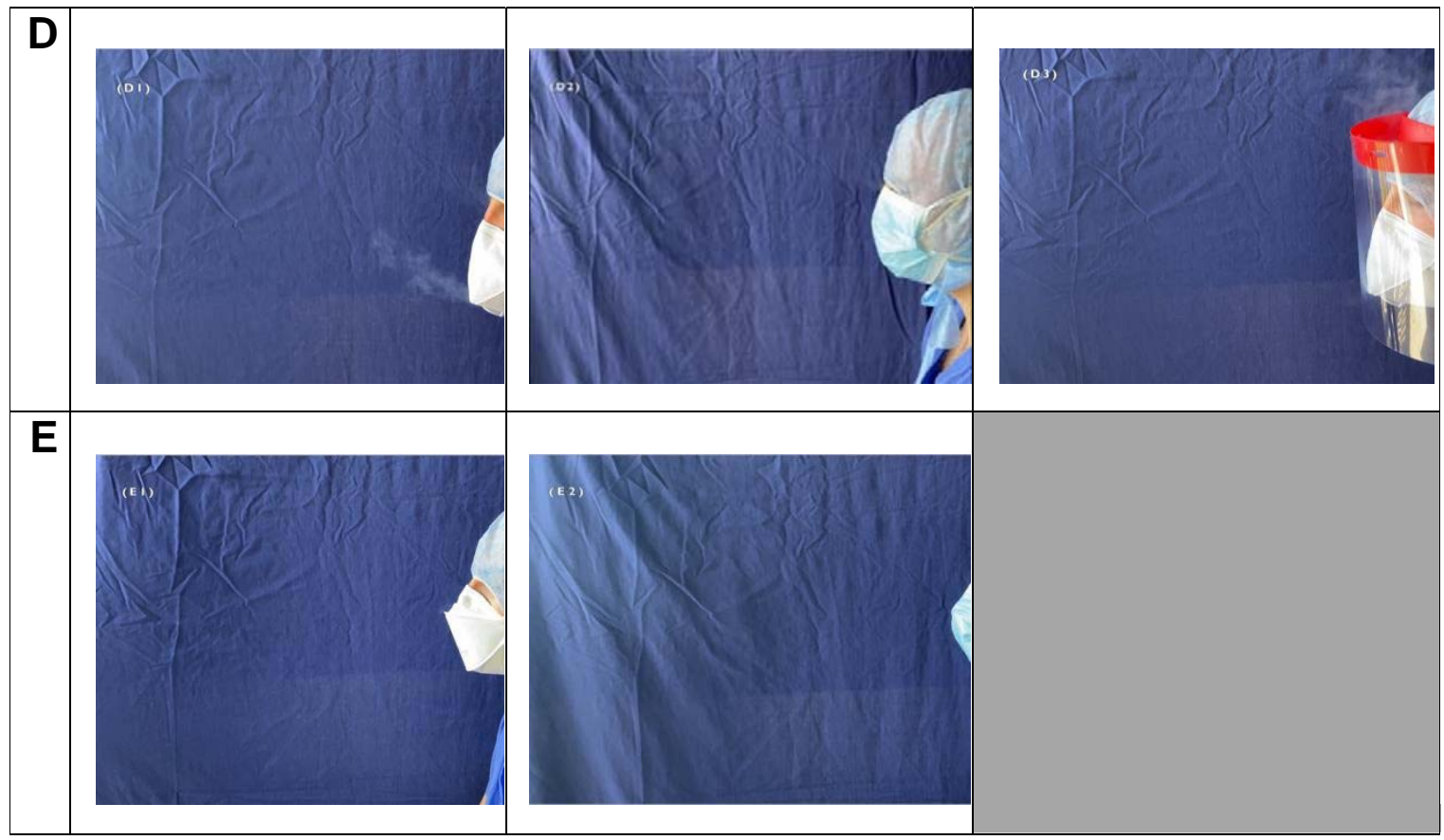

